\title{
Nutrition, Exercise, and Stress Management for Treatment and Prevention of Psychiatric Disorders. A Narrative Review Psychoneuroendocrineimmunology-Based
}

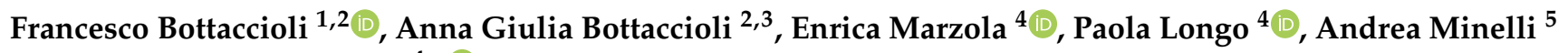 \\ and Giovanni Abbate-Daga $4, *$ (D) \\ 1 Department of Life, Health and Environmental Sciences, University of L'Aquila, 67100 L'Aquila, Italy; \\ francesco.bottaccioli@gmail.com \\ 2 Italian Society of Psychoneuroendocrineimmunology (SIPNEI), 00195 Rome, Italy; \\ annagiulia.bottaccioli@gmail.com \\ 3 Faculty of Psychology, University "Vita e Salute" San Raffaele, 20132 Milan, Italy \\ 4 Eating Disorders Center, Department of Neuroscience, University of Turin, 10126 Turin, Italy; \\ enrica.marzola@unito.it (E.M.); paola.longo@unito.it (P.L.) \\ 5 Department of Biomolecular Sciences, University of Urbino Carlo Bo, 61029 Urbino, Italy; \\ andrea.minelli@uniurb.it \\ * Correspondence: giovanni.abbatedaga@unito.it
}

Citation: Bottaccioli, F.; Bottaccioli, A.G.; Marzola, E.; Longo, P.; Minelli, A.; Abbate-Daga, G. Nutrition, Exercise, and Stress Management for Treatment and Prevention of Psychiatric Disorders. A Narrative Review

PsychoneuroendocrineimmunologyBased. Endocrines 2021, 2, 226-240. https://doi.org/10.3390/

endocrines 2030022

Academic Editor: Antonio Brunetti

Received: 20 May 2021

Accepted: 26 July 2021

Published: 29 July 2021

Publisher's Note: MDPI stays neutral with regard to jurisdictional claims in published maps and institutional affiliations.

Copyright: (c) 2021 by the authors. Licensee MDPI, Basel, Switzerland. This article is an open access article distributed under the terms and conditions of the Creative Commons Attribution (CC BY) license (https:// creativecommons.org/licenses/by/ $4.0 /)$.

\begin{abstract}
Psychoneuroendocrineimmunology (PNEI) brings together knowledge acquired since the 1930s from endocrinology, immunology, neuroscience, and psychology. With PNEI, a model of research and interpretation of health and disease is emerging, which sees the human body as a structured and interconnected unit, where the psychological and biological systems are mutually coordinated. In the PNEI view, many factors could influence mental health, with the endocrine system involved in mediating the effects of environmental stress on mental health and inflammation in the onset and course of psychiatric disorders as a result of individual and collective conditions and behaviors. Among these, nutrition is one way by which the environment impacts physiology: indeed, many pieces of research showed that several elements (e.g., probiotics, fish oil, zinc) have a positive effect on mental disorders thus being potentially augmentation agents in treatment. Still, physical activity can moderate depressive symptoms, while prolonged stress increases the risk of psychopathology. Taken together, the PNEI-based approach may inform prevention and treatment strategies, also in the field of mental health care.
\end{abstract}

Keywords: endocrine system; food; physical activity; psychiatry; inflammation; depression; anxiety

\section{Introduction}

Since the 19th century, disorders and diseases of the mind have been split into neurological and psychiatric disorders and entrusted to two different medical approaches. Neurological disorders are by definition the result of brain injury and have in the last centuries achieved the status of true pathologies. Psychiatric disorders, on the other hand, have long been lost in the fog of mental symptoms without "focal brain injury". The last century has seen a shift from the domain of psychoanalytic psychiatry in the first half to the domain of biological psychiatry and psychopharmacology. The turning point in psychiatry came in the late 1970s, when the American Psychiatric Association [1], speaking through its Chairman Melvin Sabshin, launched into a "vigorous effort to re-medicalize Psychiatry" fighting on two fronts: against the historic power of psychoanalysis and the fledgling mortal threat represented by anti-psychiatry [2]. With the third edition of the Diagnostic and Statistical Manual of Mental Disorders (DSM), published in 1980, a complete adherence of Psychiatry to the biomedical model is achieved. The psychiatric identity 
crisis seemed to be definitively resolved. In fact, after two decades of apparent triumph, the crisis has reappeared.

Gardner C, Kleinman A. on New England Journal of Medicine wrote: "Biologic psychiatry has far failed to produce a comprehensive theoretical model of any major psychiatric disorder, any tests that can be used in a clinic to diagnose clearly defined major psychiatric disorders, or any guiding principle for somatic treatments to replace the empirical use of medications" [3].

The promises of biological psychiatry, based on the extensive and punctual use of psychotropic drugs, have been broken on the rocks of controlled empirical research that has documented the not sufficiently effectiveness of the chemical molecules proposed in the last 50 years in the face of significant adverse effects on numerous systems including the central nervous system, if used beyond the necessary time [4], also of selected birth deficits as in the case of the use of antidepressants during pregnancy [5].

Of course, "biologic knowledge is foundational to good psychiatry" [3], but what biology? Human biology is modulated by mental activity. The in vivo investigation of the human brain, through brain-imaging, has shown that psychological interventions have effects on the function and anatomical structure of brain circuits [6]. In addition, the epigenetic investigation has further demonstrated that psychological and body-mind interventions induce changes in gene expression coding for brain receptors and neurotransmitters, thus providing a way of scientific explanation on the mechanisms of action of effective psychological interventions in the treatment of mental disorders $[7,8]$. At the same time, nutrition and physical activity play a significant role in the modulation of mental and emotional states. The evidence of effectiveness is now numerous, as shown by studies describing advantages from the administration of certain nutrients as augmentation therapies, and the good effects of physical activities on brain plasticity and epigenetics [9-12]. Ignoring these pieces of evidence is no longer possible for those who deal with mental health, both as a single professional and as a dedicated health facility.

A barrier to accepting this evidence is the reductionist biomedical paradigm, which divides the mind from body and society from biology.

Armstrong and Asch in a recent commentary [13] highlight two opposing models of disease, social and biological, that have dominated the medical approach for more than a century. According to the Authors, this divide limits impact of biomedical achievements.

In the light of these shreds of evidence, a more integrated vision of medicine is needed, a different paradigm that considers all the active aspects in contributing to the health of the individual, including the role of the endocrine system. This paradigm can be conceptualized as Psychoneuroendocrineimmunology.

Psychoneuroendocrineimmunology (PNEI) brings together, in a single model, knowledge acquired since the 1930s from endocrinology, immunology, neuroscience, and psychology. The PNEI model of health and disease sees the human body as a complex and interconnected unit, where the psychological and biological systems are mutually coordinated. The new integrated approaches provide the theoretical and practical basis to the prevention and treatment of non-communicable diseases, those of competence of both internists and psychiatrists; likewise, allow to go beyond the historical-philosophical contrast between mind and body, and overcome the twentieth-century scientific reductionism which assign the body to the medicine and the psyche to the psychology.

This narrative review on nutrition, exercise, and stress management for treatment and prevention of psychiatric disorders is therefore Psychoneuroendocrineimmunology-based with a focus on stress and the neuroendocrine system.

\section{A New Psychopathological Model}

Biology is undergoing an exciting moment, at present underway, bridging the abyss that has separated the area of human biology from that of social history. The biological sciences are the driving force of a landmark revolution. The reductionist and determinist framework has given way to a new vision that no longer sees the genome as a headquarters 
imparting instructions to the organism, but rather as an adaptive device that responds to environmental requirements by regulating gene expression. Epigenetics is a rapidly expanding science that researches molecular mechanisms through which the environment and individual life act based on the information contained in the genome. These new lines of research clarify the relations existing among the very early stages of life, starting from conception, and the health of the child and adult [14]. They offer us an explanation of the molecular mechanisms, stress-related and inflammation-based, with which characteristic features influence our mental health (pollution, diet, sedentary lifestyle, stress, social position, gender).

Mental balance can be influenced by a variety of factors: endogenous and biological, such as the microbiota and the immune system [15], environmental, such as exposure to environmental pollution [16]; behavioral, such as nutrition [17] and sedentary lifestyle $[18,19]$, social status $[20,21]$.

In this view, the endocrine system plays a pivotal role in mediating the effect of the environmental stress on the health of individuals through direct effects [22] and epigenetic modifications [23].

In short, it is possible to bring to the horizon of contemporary medicine the evaluation of the individual as a whole (see Figure 1 showing depression as an example).

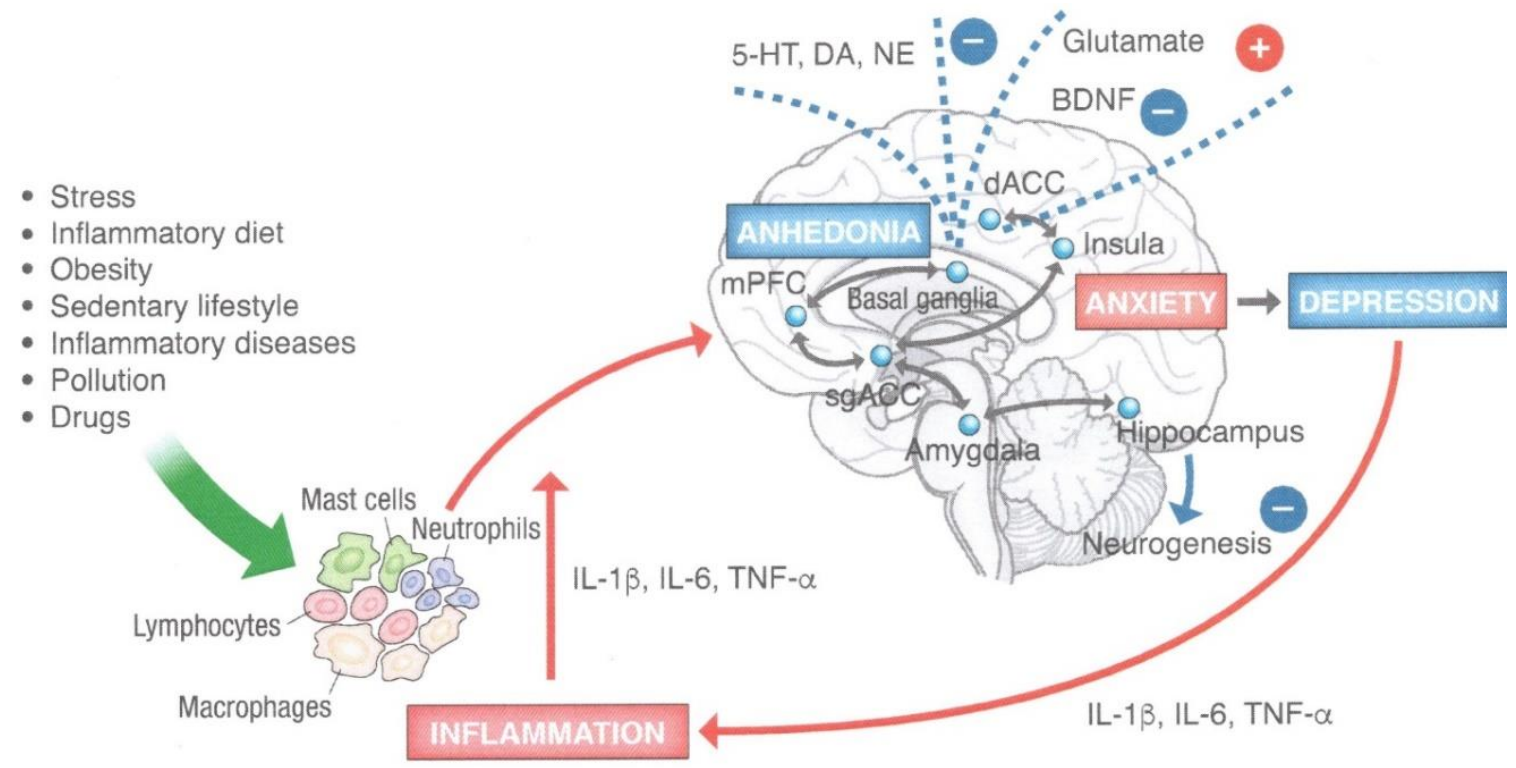

Figure 1. The bidirectional relationship between depression and inflammation. The image illustrates the inflammatory effects of several factors, starting with stress. The release of inflammatory cytokines by immune cells alters the metabolism of fundamental neurotransmitters such as serotonin, norepinephrine, dopamine, BDNF, and glutamate, reducing the levels of the first four and increasing those of the last. These alterations negatively affect the activity of strategic brain areas and their mutual connections. There are psychological consequences, with the inability to experience pleasure (anhedonia), anxiety, depression, and poor self-esteem; and biological, with alterations in the medial prefrontal cortex, the anterior cingulate cortex, the basal ganglia, the amygdala, the hippocampus, and the insula. 5-HT = serotonin; BDNF = brain-derived nerve factor; $\mathrm{DA}=$ dopamine; $\mathrm{dACC}=$ dorsal anterior cingulate cortex; $\mathrm{mPFC}=$ medial prefrontal cortex; $\mathrm{NE}=$ norepinephrine; sgACC = subgenual anterior cingulate cortex. Reprinted with permission from: F. Bottaccioli, A.G. and Bottaccioli (2020). Copyright 2020 Edra.

\section{Inflamed Mind}

Immunopsychiatry is an emerging research area investigating immune dysregulation in the pathogenesis of mental disorders, with specific regard to depression [24,25]. Recently, several meta-analyses documented clinical depression as a pro-inflammatory state [26,27], and anti-inflammatory added on standard treatment showed improvement of psychotic disorders [28]. The two dimensions, the psychological and the biological, must always 
be kept together; only in this way can we explain why inflammation can, for example, make a person less available to novelties (by altering the hippocampus and substantia nigra) [29] and more willing to see dangers rather than opportunities (by altering the ventral striatum) [30], as experimental studies on healthy volunteers showed, who were subjected to inflammatory stimuli while their brain was in the functional magnetic resonance scanner.

However, from the new studies on the role of inflammation, research, and clinical practice, under the powerful push of the pharmaceutical industry, may be looking to propose the use of anti-inflammatory drugs, either traditional or new ones, to be paired with psychiatric drugs. This option, in the case of traditional anti-inflammatories, is not without risk, as documented by a large study on the Danish population [31], which even indicates a strong increase in mortality, especially from cardiovascular causes, linked to the combination of antidepressants and some anti-inflammatories, including diclofenac and paracetamol. A risk that would further add to an extortionate expenditure if it were decided to spread the use of anti-TNF-a monoclonal antibodies, as several parties have proposed.

Inflammation, as the main pathway that influences the genesis and consolidation of mental disorders, occurs not only as a result of stress but also from individual (obesity, inflammatory diseases) and collective (pollution) conditions and behaviors (inflammatory diet, sedentary lifestyle, taking medicines and drugs) [32]. Below we review the main physiological and clinical evidence of nutrition, exercise, and stress management for the treatment and prevention of psychiatric disorders.

\section{Nutrition}

"There is growing scientific evidence that shows that dietary modifications have strong positive and negative effects on health over the course of one's life"-wrote the World Health Organization in a 2003 document [33], indicating the return of the centrality of nutrition for human health after its blackout in the second half of the twentieth century. The next recent advancement of note is epigenetic research. Epigenetics is the study of changes in gene expression that are not caused by genetic mutations and that may be heritable. Epigenetics indicates a pattern of gene expression that conditions cell activity in response to environmental stimuli. All cells can receive an epigenetic signature: neurons, immune cells, tissue cells of various organs. It is an adaptive change. This type of signature, linked to the state of health of the organism, may be reversible, and this is a very important point because it means that change in a particular behavior (diet, stress, drugs) can reprogram the structure of the cell.

Epigenetic research leads to a new vision of food which traditionally has been viewed as an energy supply and a provider of elements for tissue replacement, as fuel to burn for the body's activities, and also as building blocks to build and maintain the human body. In fact, food is one of the main ways in which the environment, methodically, forms the epigenome and, in this way, influences adaptive responses, metabolism, the immune system, and the brain; in short, the whole physiology of the body.

In the last decades, diet has become a topic of great interest in psychiatry [34] both because people with severe psychiatric disorders have a poor-quality diet and because it has become clear that diet can positively influence the state of mind and psychiatric symptoms. In a seminal paper, in 2008, it was documented that excessive caloric intake causes inflammation of the hypothalamus [35], a crucial cerebral area both to energy balance and neuroendocrine system control-stress system including. In addition, further biological pathways could plausibly link diet with mental health: inflammation, oxidative stress, mitochondrial signaling, tryptophan-kynurenine metabolism, gut microbiota composition [36].

It is documented that the intake of red meat increases inflammation. A meta-analysis based on 241,738 participants showed a significant association between red and processed meat intake and risk of depression [37]. Recently it was shown that a high-fat diet elevates glucose-dependent insulinotropic polypeptide (GIP), which promotes hypothalamic inflammation and insulin resistance [38]. GIP is a gut-derived hormone. 
The Gut-brain axis, although poorly considered in medical education [39], has won a prominent place in neuroscientific research, which highlights gut-brain bidirectional relation [40]: the brain controls hunger and satiety, and the gut influences the modulation of social behavior, emotion, stress response. The picture has become more completed with the study of gut microbiota, which includes vast ecosystems composed of an exorbitant number of microbes, including viruses, fungi, bacteria. They have several important roles in digestion, metabolism, vitamin, and short-chain fatty acids (SCFAs) synthesis, and immune regulation. Numerous neuroactive substances are released from the microbiota and, through blood circulation and ascending autonomic nervous fibers (vagus nerve particularly), reach the brain. Those substances are neurotransmitters (GABA, dopamine, noradrenaline, acetylcholine); SCFAs, including acetate, butyrate, propionate, and lactate; bile acids and tryptophan metabolites. Furthermore, the intestinal mucosa harbors a large portion of the immune system, called the mucosal immune system, which interfaces with the microbiota, controlling its potentially pathogenic strains. An excessive presence of the latter can cause an inflammatory response, which can be increased by an alteration of the intestinal barrier. Stress, with cortisol overproduction, makes the intestinal wall more permeable to microorganisms (leaky gut) increasing pro-inflammatory cytokines which can then signal to the brain via circulatory and autonomic systems [41].

The Gut-brain axis is, therefore, more correctly referred to as the microbiota-gutbrain axis. Intestinal microbiota alterations have been related to mood disorders, anxiety, and depression, and also to Schizophrenia, Bipolar disorder, Anorexia nervosa, and other neuropsychiatric diseases such as Alzheimer's, Parkinson's, Autism, and Multiple Sclerosis [42].

According to a recent review, the gut microbiota of patients with Major Depression Disease (MDD) shows profound taxonomic changes associated with increased bacterial pro-inflammatory products, reduced Short Chain Fatty Acids (SCFAs) synthesis, impaired intestinal barrier integrity, and altered neurotransmitter production [43].

Scientific research about butyrate, a short-chain fatty acid metabolite derived from intestinal bacterial fermentation of dietary fibers, has demonstrated that it improves learning and memory in animal models through molecular epigenetic changes in histone tails. Experimental models provided by Leclercq et al. show that the transplantation of gut microbiota from alcoholic patients to germ-free mice reduces b-hydroxybutyrate synthesis and affects hepatic and adipose tissue metabolism resulting in neurological and behavioral alterations in recipient mice [44]. In summary, an anti-inflammatory diet, like the Mediterranean diet [45], can beneficially influence mental health by modulating inflammation, oxidative stress, metabolites microbiota-based, and other pathways that from peripheric systems reach to the brain.

\section{Nutraceutical and Diet Supplements}

\subsection{Probiotics}

Dynan (2103) proposed to classify probiotics affecting mood and cognitive state as psychobiotics [46]. Recently [47], has been proposed to include all probiotics and prebiotics that influence microbiota-brain relationships in the class of psychobiotics. The microorganisms recognized as agents with psychotropic function are: including Streptococcus thermophiles, Bifidobacterium animalis, Bifidobacterium bifidum, Bifidobacterium longum, Streptococcus thermophiles, Lactobacillus bulgaricus, Lactococcus lactis, Lactobacillus acidophilus, Lactobacillus plantarum, Lactobacillus reuteri, Lactobacillus paracasei, Lactobacillus helveticus, Lactobacillus rhamnosus, and others [48].

A clinical study showed that four weeks of therapy with Bifidobacterium longum-based probiotics reduced anxiety and stress, improved cortisol secretion and visuospatial memory in 22 healthy volunteers [49].

In a randomized controlled trial with a placebo, the consumption of $3 \mathrm{~g} /$ day of oral suspension containing nine probiotic strains for 12 weeks significantly reduced anxiety in 
subjects with inflammatory risk factors [50]. However, in order to confirm these preliminary results, more numerous randomized controlled trials (RCTs) are needed.

The Cryan and Dinan group recently conducted a systematic review and detected nine RCTs. Four RCTs included patients with schizophrenia, five RCTs patients with depression, and one RCT patient with generalized anxiety disorder (GAS). The authors' analysis concludes that, although with low effect size, probiotics could improve depressive symptoms and anxiety, without significate results for schizophrenia.

A meta-analysis including ten clinical trials and 685 participants was conducted to study the effectiveness of probiotics on participants under stress conditions or with a depression or anxiety diagnosis [51]. Subgroup analysis showed that probiotics were effective on depressive symptoms just in patients with depression, instead no significant changes were observed under stress elicitation and in anxiety patients.

Conversely, a systematic review and meta-analysis of RCTs including 1146 volunteers revealed that probiotics can mitigate subjective stress, but more evidence from clinical trials is needed to confirm these results [52].

In conclusion, probiotics hold promise as an adjunct to the treatment of mental disorders, depression in particular, while there is much less evidence for anxiety and symptoms stress-related.

\subsection{Fish Oil}

The long-chain polyunsaturated fatty acid (LCPUFAs) omega-3 family is the most abundant fatty acid type in fish oil. Meta-analyses showed that, in people with depression and other psychiatric disorders, there is a reduction in LCPUFAs in the cell membrane [53]. Some randomized controlled trials give a net superiority of omega- 3 over placebo (olive oil) [54], while a Cochrane Review does not draw a definitive conclusion because, it argues, although the statistical superiority of omega- 3 is evident compared to the placebo, the clinical significance of these results is not yet clear [55]. However, recently the International Society for Nutritional Psychiatry Research (ISNPR) has reached the highest agreement on the statement for omega-3 PUFAs oral supplementation, recommended it as an adjunctive treatment for adults diagnosed with MDD [56].

Fish oil has also been tested in the treatment of other mental disorders, such as schizophrenia, which is characterized by high comorbidity of metabolic disorders and lowgrade inflammation. A 12-weeks randomized controlled trial tested the efficacy of omega-3 fatty acid in reducing triglyceride levels and TNF- $\alpha$ cytokine among 80 patients with both schizophrenia and metabolic syndrome who were taking olanzapine in monotherapy [57]. Subsequently, the same research team showed that fish oil supplementation provided beneficial effects on cognitive function in patients comorbid with schizophrenia and metabolic syndrome. The clinical feature is paralleled by an enhanced brain-derived neurotrophic factor (BDNF) and reduced TNF- $\alpha$ levels [58].

There are promising findings in experimental research on omega- 3 fatty acids administration in several psychiatric disorders, including major depression, bipolar disorder, personality disorders, high-risk subjects to psychotic event, attention-deficit hyperactivity disorder, and autism spectrum disorders. Initial findings in this field are promising according to a recent systematic review [59].

Fish oil has been investigated in the prevention of the first psychotic episode (FEP). G. Paul Amminger, Vienna University, actually at Centre for Youth Mental Health, The University of Melbourne, in the last decade led to a series of clinical and laboratory studies. A first RCT demonstrated a reduction in conversion into the FEP of ultra-high-risk (UHR) subjects treated with fish oil supplementation [60]. A significant reduction of the risk for transition to psychosis and psychiatric morbidity in general, with a prolonged median time of 6.7 years, was observed [61]. In a subsequent RCT including 304 patients, fish oil adjunct to good-quality psychosocial treatment showed no evidence of superior efficacy for $\omega-3$ PUFAs. The outcome's analysis was equally positive in both $\omega-3$ PUFA and placebo groups, with low transition rates and overall symptomatic improvement [62]. 
However, the analysis of erythrocyte PUFA levels in the omega-3 group showed that n-3 index (derived from n-6: n-3 ratio, docosahexaenoic acid (DHA), and eicosapentaenoic acid (EPA) level) negatively correlated with psychopathology scores, as well as with psychotic, depressive and manic symptoms [63].

Deficiencies in membrane PUFAs, in particular the omega-3 (n-3) series, can drive to poor control of cerebral inflammation, contributing to molecular processes underlying psychotic disorders. This inflammation-related molecular evidence deserves further research and clinical trials.

\subsection{Zinc}

This mineral is a necessary component of the synthesis of hundreds of enzymes and other proteins. It is required for the correct structure and maintenance of cell membranes and is involved in the regulation of the immuno-neuro-endocrine network. One of its deficits creates neurological problems, among others. Zn deficiency affects almost $17 \%$ of the global population [64]. In a Japanese study, about $20 \%$ of the elderly and over a third of children under the age of 4 had a zinc deficiency [65]. Depressed and older patients [66], have a reduction in zinc levels in their blood. Studies on animal models and, in the last ten years, human studies have documented the efficacy of zinc supplementation in association with standard treatment [67] or even in monotherapy [68]. The mechanism of action of zinc appears to be as a glutamate antagonist at the NMDA receptor level and so in this way, it increases BDNF, neural plasticity, and neurogenesis. However, cerebral zinc homeostasis is crucial because zinc high level is associated with neurodegenerative diseases [69].

\subsection{N-Acetylcysteine (NAC)}

This molecule has a potent antioxidant effect since it enters into synthesis with glutathione, the main tripeptide antioxidant at the cytoplasmic level in cells. Glutathione (GSH) plays a relevant role in the brain as an antioxidant. Recently, low GSH levels have been observed in several psychiatric diseases, including stress-related psychopathologies [70]. NAC has been used with positive effects in several psychiatric disorders (i.e., depression, schizophrenia, bipolar disorder, and obsessive-compulsive disorder (OCD)). In an RCT involving OCD patients, N-acetylcysteine was given to one group (NAC, $2 \mathrm{~g}$ per day) in addition to the antidepressant fluvoxamine for 10 weeks; another group took the same antidepressant along with a placebo. The recording of symptoms at four, eight, and ten weeks showed a statistically significant reduction in symptoms in the NAC group compared to the placebo [71]. Other RCTs have documented moderate efficacy of NAC. The N-acetylcysteine treatment reaches clinical benefit in some cases of refractory OCD reducing anxiety symptoms in treatment-resistant OCD patients [72]. As remarked by the recent position statement by the International College of Obsessive-Compulsive Spectrum Disorders, NAC is involved in the modulation of glutamate signal implicated in the pathogenesis of OCD [73].

An RCT on approximately 250 patients with depression showed that, after 16 weeks of treatment, adding $2 \mathrm{~g}$ per day of NAC to standard treatment (pharmacological or psychotherapeutic) produces effects superior to the placebo [74]. A systematic review of NAC warns that further confirmations are needed to definitively conclude on the efficacy of the amino acid in the treatment of depression [75].

Systematic review and meta-analysis of RCTs recently showed that N-acetylcysteine seems to reduce Clinical Global Impression-Severity Scale (CGI-S) score, although no specific improvements in symptoms have been assessed [76]. More human research is recommended because animal research continues to document the beneficial effects of NAC on depressive and anxiety behaviors [77]. 


\subsection{Vitamin $D$}

Low levels of vitamin D have been found in studies in depressed patients [78]. The first controlled studies showed that improving the levels of the vitamin in the blood, also improves the mood and well-being of young and old [79].

A prospective study on 139,128 adults included in the UK Biobank found the associations between low serum vitamin D level at the baseline (years 2006-2010) and new-onset depression at the follow-up period in 2016 [80].

Association between gestational and post-partum depression has been investigated. A systematic review of multicenter studies comprising 8583 women found that Vitamin D deficiency is a risk factor that predisposes to gestational and postpartum depression [81]. Vitamin D supplementation could therefore represent a promising therapy for reducing depressive symptoms in women during the peri-partum period.

\section{Physical Activity}

It has been estimated that physical activity leads to several benefits such as an improvement in glucose metabolism and a lower risk of many cardiovascular diseases [82]. Moreover, researchers described a positive effect of exercise on psychological symptoms and psychiatric disorders [82]. Relatedly, Guidelines have been developed by numerous scientific societies and authorities, such as the UK Royal College of Psychiatrists [83], European Psychiatric Association, which recommend "structured exercise training as an effective first-line treatment option for moderate depression, and as adjunctive intervention for improving symptomatic recovery in several mental illness" [84]. Two recent metareview, that is, which examined the meta-analysis and systematic reviews of controlled studies, have concluded that there is "convergent evidence indicating the use of physical activity in primary prevention and clinical treatment across a spectrum of mental disorders" [85], including depression, anxiety, attention-deficit hyperactivity disorder (ADHD), substance use disorder, and reduction schizophrenia symptomatology [86].

The combination of meditation and movement, which is widespread in oriental traditions, is of great interest. One example of this is Tai Ji Quan; however, it can also be practiced by applying meditative techniques such as concentration and focusing on normal physical exercise. Experiences in this sense are being carried out on patients who present high levels of anxiety or uncontrolled emotions and also lack of fluidity of movement [87], and depression [88].

Several theories tried to explain the mechanisms through which physical activity acts on mental health. For instance, regular physical activity has high scientific evidence of modification in the brain of three essential neurotransmitters: dopamine, serotonin, and norepinephrine. At the same time, cannabinoids and brain growth and plasticity factors (IGF-1) reach the brain, having entered the bloodstream through muscular contraction. A finding established by research on animals as well as humans is the increase in brainderived nerve factor (BDNF), which has antidepressant and nerve-plasticity stimulating functions [89].

According to other biologic hypotheses, the thermogenic one, the increase of temperature in certain brain region after exercise is involved in the reduction of muscle tension leading thus relaxation and lower anxiety levels [90]. Other authors stated that, in biological terms, exercise acts like an antidepressant medication; in this context, habitual physical activity decreases the levels of stress hormones produced by the HPA axis contributing to ameliorate depressive symptoms and reduce the stress reactivity [91]. However, physical activity must be managed with caution since it could lead to negative effects (e.g., vulnerability to infections, behavioral and psychological disorders) when it is practiced in a compulsive and addicted way [92]. This is particularly true in patients with eating disorders, in which exercise is driven by body dissatisfaction and general body image alterations. Indeed, Riva and colleagues (2021) described a worse clinical picture in patients with acute anorexia nervosa who practiced high physical activity compared to patients without habitual exercise [93]. However, if controlled and added to treatment protocols, 
physical activity could be effective even on core features of eating disorders (e.g., body dissatisfaction, drive for thinness), as shown by Balciuniene and colleagues (2021) [94]. Moreover, physical activity can be effectively added to psychotherapy and nutritional protocols for patients with obesity and binge eating disorders [95]. To conclude, physical activity could represent an effective and economic tool to promote psychological wellbeing, especially in the case of depressive and anxious symptoms, on which the scientific evidence is prevalent.

\section{Stress Management and Psychological Interventions}

Stress is a physiological response of the organism, multisystemic and integrated, to any need: of a biological nature (e.g., viral infection), and of a mental nature (emotional and/or cognitive). A response that in the short term (acute stress) promotes dynamic phenomena of adaptation of the organism to the most varied environmental conditions but which, if it occurs too frequently and/or for long periods (chronic stress), and most importantly, if the stress is beyond our ability to control (coping), can have long-lasting dysfunctional effects on different biological systems (nervous, immune, endocrine and metabolic) and pathological consequences on various organs and systems (allostatic load) [96].

Prolonged stress leads to hypotrophy and reduced activity of the Prefrontal Cortex, a key brain structure implied in working memory, context appraisal, executive, and self-regulatory functions. Hippocampus, which is crucial for memory, mood, and Hypothalamus-Hypophysis-Adrenal (HPA) axis regulation, can be injured by chronic stress via cortisol exposure [97]. Moreover, multiple adverse events during lifespan correlate with th reduction of many brain areas involved in emotions regulation, like the medial prefrontal cortex, anterior cingulate cortex, and insular cortex. These morphological and functional changes in neural circuits enhance long-term risks for psychopathology occurrence, in particular depression, anxiety, post-traumatic stress disorder (PTSD), and addiction [98]. Research on neurobiology of psychiatric diseases evidences structural remodeling of the hippocampus and PFC, as well as clinical conditions characterized by chronic stress often associated with cognitive deficits, dysregulated cortisol secretion, altered metabolic signals, and immune imbalance which finally result in inflammation [99]. Epigenetics is regarded as a molecular pathway mediating the transduction of chronic stress into multiple potential patterns of gene expression [100]. Epigenetic signature of HPA axis, namely the gene coding for the glucocorticoid receptor (NR3C1), as well as the signature gene coding NFkB, main inflammatory intracellular pathway, and other signature genes related to neurotransmitters (serotonin, GABA) and neurohormone (oxytocin), neuropeptide (BDNF), enzyme (mono-amino-oxidase $\mathrm{A}, \mathrm{MAO}-\mathrm{A}$ ), it is thought to be some of the molecular mechanism underlying the pathogenesis of the psychiatric disorder.

Research in this field is growing. A recent study compared methylation levels of the oxytocin receptor gene in patients with obsessive compulsive disorder (OCD) and healthy controls. Increased methylation was found in the OCD group. In this group, hypermethylation was associated with stressful life events. Interestingly, even in healthy controls, childhood adversities were linked to increased methylation of the oxytocin receptor gene [101]. Therefore, early life stress and major life stress events can produce a decrease in gene expression of the oxytocin receptor with alteration of the neurohormone signal, which is essential for social relationships.

When psychological and mind-body interventions work, it not only improves the mental state and well-being of the person but changes the epigenetic signatures [102]. It has been deeply described the mechanistic pathways involved in epigenetic reversion of HPA axis activity and in the down-regulation of inflammatory transcriptional response (mainly via NF-kB) that underpin the ability to respond effectively to stress, thus improving resilience and clinical and biological recovery of both mood and immunity balance [103]. It has been demonstrated a reduced methylation of the BDNF gene, thus leading to enhanced gene expression, in patients with eating disorders who undergo behavioral therapy sessions, and this correlated with clinical improvement of specific symptoms. In patients 
with PTSD, Prolonged Exposure Therapy (PET) leads to neurobiological responses which can be measured through epigenetic modifications in key stress-related genes. In fact, in greater responders to psychotherapy intervention, there is a significant reduction in methylation of the GR gene (NR3C1) that directly correlates with higher baseline levels of cortisol (frequently low in PTSD), and a decrease in cortisol reactivity under stress tasks $[104,105]$.

A growing body of research has investigated the effects of mind-body therapies (MBTs), like meditation, tai chi, qi gong, yoga, on biological markers of mind inflammation.

A seminal review by Bower and Irwin [106] which have included 26 trials, confirmed the anti-inflammatory effects of MBTs on circulating markers of inflammation, such as c-reactive protein (CRP). Two controlled studies PNEIMED (Meditation Psychoneuroendocrineimmunology-based), in healthy middle-aged and young volunteers, showed a reduction of salivary cortisol under basal and stressful conditions $[9,107]$.

A field of growing interest concerns cellular aging as measured by the length of telomeres, which are the end cap of chromosomes. Telomeres give stability to the genetic material contained in chromosomes. A shortening of the telomere length is a marker of cellular aging, exposing it to aging-related diseases, including cancer, autoimmunity, and depression.

A systematic review, which investigated the effects of meditation on telomere length, found positive effects on telomere length of two randomized controlled trials and three case control studies of high and moderate quality, although only one randomized trial and one case control study obtained statistical significance [108].

Recently, a systematic review and meta-analysis of RCTs regarding the effects of psychosocial interventions on the immune system [109] found that, across 56 RCTs and 4060 participants, psychosocial interventions, including Cognitive Behavioral Therapy and other psychotherapy, are associated with a reduction of inflammatory markers and an increase of antiviral immunity.

\section{Conclusions}

In conclusion, the regulation of stress and its impact on the brain is central to the physical and mental health of the individual. While medicine has a clear understanding of the use of drugs to treat people, much scientific evidence points to the central role of nutrition, exercise, and stress management in personal care. In close connection with the immune system and the brain, the HPA axis is crucial for the balance between physiological reactivity and distress. Chronic alterations of this system, epigenetic modification, stress management anomalies, inflammatory nutrition, dysbiosis, sedentary lifestyle should be considered in the health promotion and the treatment of mental disorders.

Author Contributions: Conceptualization: F.B., A.G.B., G.A.-D.; methodology: F.B., A.G.B., A.M., E.M., writing-original draft preparation: F.B., G.A.-D.; writing-review and editing: P.L., E.M., A.G.B., A.M., G.A.-D.; supervision: F.B. All authors have read and agreed to the published version of the manuscript.

Funding: This research received no external fundings.

Conflicts of Interest: The authors declare no conflict of interests.

\section{References}

1. American Psychiatric Association. Diagnostic and Statistical Manual of Mental Disorders, 5th ed.; APA: Washington, DC, USA, 2013. [CrossRef]

2. Angell, M. The epidemic of mental illness: Why? N. Y. Rev. 2011, 58, 20-22.

3. Gardner, C.; Kleinman, A. Medicine and the Mind-The Consequences of Psychiatry's Identity Crisis. N. Engl. J. Med. 2019, 381, 1697-1699. [CrossRef] [PubMed]

4. Voineskos, A.N.; Mulsant, B.H.; Dickie, E.W.; Neufeld, N.H.; Rothschild, A.J.; Whyte, E.M.; Meyers, B.S.; Alexopoulos, G.S.; Hoptman, M.J.; Lerch, J.P.; et al. Effects of Antipsychotic Medication on Brain Structure in Patients with Major Depressive Disorder and Psychotic Features. JAMA Psychiatry 2020, 77, 674-683. [CrossRef] [PubMed] 
5. Anderson, K.N.; Lind, J.N.; Simeone, R.M.; Bobo, W.V.; Mitchell, A.A.; Riehle-Colarusso, T.; Polen, K.N.; Reefhuis, J. Maternal Use of Specific Antidepressant Medications During Early Pregnancy and the Risk of Selected Birth Defects. JAMA Psychiatry 2020, 77, 1246-1255. [CrossRef]

6. Skottnik, L.; Linden, D.E.J. Mental Imagery and Brain Regulation-New Links Between Psychotherapy and Neuroscience. Front. Psychiatry 2019, 10. [CrossRef]

7. Jiménez, J.P.; Botto, A.; Herrera, L.; Leighton, C.; Rossi, J.L.; Quevedo, Y.; Silva, J.R.; Martinez, F.; Assar, R.; Salazar, L.A.; et al. Psychotherapy and Genetic Neuroscience: An Emerging Dialog. Front. Genet. 2018, 9, 257. [CrossRef]

8. Dossett, M.L.; Fricchione, G.L.; Benson, H. A New Era for Mind-Body Medicine. N. Engl. J. Med. 2020, 382, 1390-1391. [CrossRef]

9. Bottaccioli, F.; Bottaccioli, A.G. Psychoneuroendocrineimmunology and Science of Integrated Care. The Manual; Edra: Palm Beach, FL, USA, 2020.

10. Sarris, J.; Logan, A.C.; Akbaraly, T.N.; Amminger, G.P.; Balanzá-Martínez, V.; Freeman, M.P.; Hibbeln, J.; Matsuoka, Y.; Mischoulon, D.; Mizoue, T.; et al. Nutritional medicine as mainstream in psychiatry. Lancet Psychiatry 2015, 2, 271-274. [CrossRef]

11. Sarris, J. Nutritional Psychiatry: From Concept to the Clinic. Drugs 2019, 79, 929-934. [CrossRef]

12. Mandolesi, L.; Polverino, A.; Montuori, S.; Foti, F.; Ferraioli, G.; Sorrentino, P.; Sorrentino, G.; Mandolesi, L.; Polverino, A.; Montuori, S.; et al. Effects of Physical Exercise on Cognitive Functioning and Wellbeing: Biological and Psychological Benefits. Front. Psychol. 2018, 9, 509. [CrossRef]

13. Armstrong, K.; Asch, D.A. Bridging Polarization in Medicine-From Biology to Social Causes. N. Engl. J. Med. 2020, 382, 888-889. [CrossRef] [PubMed]

14. Szyf, M. The epigenetics of perinatal stress. Dialogues Clin. Neurosci. 2019, 21, 369-378. [CrossRef] [PubMed]

15. Tong, J.; Satyanarayanan, S.K.; Su, H. Nutraceuticals and probiotics in the management of psychiatric and neurological disorders: A focus on microbiota-gut-brain-immune axis. Brain Behav. Immun. 2020, 90, 403-419. [CrossRef]

16. Khan, A.; Plana-Ripoll, O.; Antonsen, S.; Brandt, J.; Geels, C.; Landecker, H.; Sullivan, P.F.; Pedersen, C.B.; Rzhetsky, A. Environmental pollution is associated with increased risk of psychiatric disorders in the US and Denmark. PLoS Biol. 2019, 17, e3000353. [CrossRef]

17. Mattson, M.P. An Evolutionary Perspective on Why Food Overconsumption Impairs Cognition. Trends Cogn. Sci. 2019, 23, 200-212. [CrossRef]

18. Zhai, L.; Zhang, Y.; Zhang, D. Sedentary behaviour and the risk of depression: A meta-analysis. Br. J. Sports Med. 2014, 49, 705-709. [CrossRef] [PubMed]

19. McDowell, C.P.; Dishman, R.K.; Gordon, B.; Herring, M.P. Physical Activity and Anxiety: A Systematic Review and Meta-analysis of Prospective Cohort Studies. Am. J. Prev. Med. 2019, 57, 545-556. [CrossRef] [PubMed]

20. Stewart-Brown, S.; Samaraweera, P.C.; Taggart, F.; Kandala, N.-B.; Stranges, S. Socioeconomic gradients and mental health: Implications for public health. Br. J. Psychiatry 2015, 206, 461-465. [CrossRef] [PubMed]

21. Giebel, C.; Corcoran, R.; Goodall, M.; Campbell, N.; Gabbay, M.; Daras, K.; Barr, B.; Wilson, T.; Kullu, C. Do people living in disadvantaged circumstances receive different mental health treatments than those from less disadvantaged backgrounds? BMC Public Health 2020, 20, 1-10. [CrossRef]

22. Shoaff, J.R.; Coull, B.; Weuve, J.; Bellinger, D.C.; Calafat, A.M.; Schantz, S.L.; Korrick, S.A. Association of Exposure to EndocrineDisrupting Chemicals During Adolescence with Attention-Deficit/Hyperactivity Disorder-Related Behaviors. JAMA Netw. Open 2020, 3, e2015041. [CrossRef] [PubMed]

23. Shi, Y.; Qi, W.; Xu, Q.; Wang, Z.; Cao, X.; Zhou, L.; Ye, L. The role of epigenetics in the reproductive toxicity of environmental endocrine disruptors. Environ. Mol. Mutagen. 2020, 62, 78-88. [CrossRef]

24. Pariante, C.M. Why are depressed patients inflamed? A reflection on 20 years of research on depression, glucocorticoid resistance and inflammation. Eur. Neuropsychopharmacol. 2017, 27, 554-559. [CrossRef] [PubMed]

25. Bauer, M.E.; Teixeira, A.L. Inflammation in psychiatric disorders: What comes first? Ann. N. Y. Acad. Sci. 2018, 1437, 57-67. [CrossRef] [PubMed]

26. Osimo, E.F.; Baxter, L.J.; Lewis, G.; Jones, P.B.; Khandaker, G.M. Prevalence of low-grade inflammation in depression: A systematic review and meta-analysis of CRP levels. Psychol. Med. 2019, 49, 1958-1970. [CrossRef] [PubMed]

27. Osimo, E.F.; Pillinger, T.; Rodriguez, I.M.; Khandaker, G.M.; Pariante, C.M.; Howes, O.D. Inflammatory markers in depression: A meta-analysis of mean differences and variability in 5166 patients and 5083 controls. Brain Behav. Immun. 2020, 87, 901-909. [CrossRef] [PubMed]

28. Jeppesen, R.; Christensen, R.H.; Pedersen, E.M.; Nordentoft, M.; Hjorthøj, C.; Köhler-Forsberg, O.; Benros, M.E. Efficacy and safety of anti-inflammatory agents in treatment of psychotic disorders-A comprehensive systematic review and meta-analysis. Brain Behav. Immun. 2020, 90, 364-380. [CrossRef] [PubMed]

29. Harrison, N.A.; Cercignani, M.; Voon, V.; Critchley, H.D. Effects of Inflammation on Hippocampus and Substantia Nigra Responses to Novelty in Healthy Human Participants. Neuropsychopharmacology 2014, 40, 831-838. [CrossRef]

30. Harrison, N.A.; Voon, V.; Cercignani, M.; Cooper, E.A.; Pessiglione, M.; Critchley, H. A Neurocomputational Account of How Inflammation Enhances Sensitivity to Punishments Versus Rewards. Biol. Psychiatry 2016, 80, 73-81. [CrossRef] [PubMed]

31. Köhler, O.; Petersen, L.V.; Mors, O.; Gasse, C. Inflammation and depression: Combined use of selective serotonin reuptake inhibitors and NSAIDs or paracetamol and psychiatric outcomes. Brain Behav. 2015, 5, e00338. [CrossRef] [PubMed] 
32. Furman, D.; Campisi, J.; Verdin, E.; Carrera-Bastos, P.; Targ, S.; Franceschi, C.; Ferrucci, L.; Gilroy, D.W.; Fasano, A.; Miller, G.W.; et al. Chronic inflammation in the etiology of disease across the life span. Nat. Med. 2019, 25, 1822-1832. [CrossRef] [PubMed]

33. WHO; FAO Expert Consultation. Diet, Nutrition and the Prevention of Chronic Diseases; WHO: Geneva, Switzerland, 2013.

34. Firth, J.; Stubbs, B.; Teasdale, S.; Ward, P.; Veronese, N.; Shivappa, N.; Hebert, J.R.; Berk, M.; Yung, A.; Sarris, J. Diet as a hot topic in psychiatry: A population-scale study of nutritional intake and inflammatory potential in severe mental illness. World Psychiatry 2018, 17, 365-367. [CrossRef]

35. Zhang, X.; Zhang, G.; Zhang, H.; Karin, M.; Bai, H.; Cai, D. Hypothalamic IKK $\beta /$ NF-kB and ER stress Link Overnutrition. Cell 2009, 135, 61-73. [CrossRef]

36. Marx, W.; Lane, M.; Hockey, M.; Aslam, H.; Berk, M.; Walder, K.; Borsini, A.; Firth, J.; Pariante, C.M.; Berding, K.; et al. Diet and depression: Exploring the biological mechanisms of action. Mol. Psychiatry 2020, 26, 134-150. [CrossRef]

37. Nucci, D.; Fatigoni, C.; Amerio, A.; Odone, A.; Gianfredi, V. Red and Processed Meat Consumption and Risk of Depression: A Systematic Review and Meta-Analysis. Int. J. Environ. Res. Public Health 2020, 17, 6686. [CrossRef] [PubMed]

38. Fu, Y.; Kaneko, K.; Lin, H.-Y.; Mo, Q.; Xu, Y.; Suganami, T.; Ravn, P.; Fukuda, M. Gut Hormone GIP Induces Inflammation and Insulin Resistance in the Hypothalamus. Endocrinology 2020, 161. [CrossRef]

39. Damasio, A. The Strange Order of Things; Vintage: New York, NY, USA, 2018.

40. Rao, M.; Gershon, M.D. The bowel and beyond: The enteric nervous system in neurological disorders. Nat. Rev. Gastroenterol. Hepatol. 2016, 13, 517-528. [CrossRef]

41. Long-Smith, C.; O’Riordan, K.J.; Clarke, G.; Stanton, C.; Dinan, T.G.; Cryan, J.F. Microbiota-Gut-Brain Axis: New Therapeutic Opportunities. Annu. Rev. Pharmacol. Toxicol. 2020, 60, 477-502. [CrossRef] [PubMed]

42. Ojeda, J.; Ávila, A.; Vidal, P. Gut Microbiota Interaction with the Central Nervous System throughout Life. J. Clin. Med. 2021, 10, 1299. [CrossRef]

43. Łoniewski, I.; Misera, A.; Skonieczna-Żydecka, K.; Kaczmarczyk, M.; Kaźmierczak-Siedlecka, K.; Misiak, B.; Marlicz, W.; Samochowiec, J. Major Depressive Disorder and gut microbiota-Association not causation. A scoping review. Prog. Neuro Psychopharmacol. Biol. Psychiatry 2021, 106, 110111. [CrossRef] [PubMed]

44. Leclercq, S.; Le Roy, T.; Furgiuele, S.; Coste, V.; Bindels, L.B.; Leyrolle, Q.; Neyrinck, A.M.; Quoilin, C.; Amadieu, C.; Petit, G.; et al. Gut Microbiota-Induced Changes in $\beta$-Hydroxybutyrate Metabolism Are Linked to Altered Sociability and Depression in Alcohol Use Disorder. Cell Rep. 2020, 33, 108238. [CrossRef]

45. Lassale, C.; Batty, G.; Baghdadli, A.; Jacka, F.; Villegas, A.S.; Kivimäki, M.; Akbaraly, T. Healthy dietary indices and risk of depressive outcomes: A systematic review and meta-analysis of observational studies. Mol. Psychiatry 2018, 24, 965-986. [CrossRef] [PubMed]

46. Dinan, T.G.; Stanton, C.; Cryan, J. Psychobiotics: A Novel Class of Psychotropic. Biol. Psychiatry 2013, 74, 720-726. [CrossRef] [PubMed]

47. Sarkar, A.; Lehto, S.; Harty, S.; Dinan, T.; Cryan, J.F.; Burnet, P.W. Psychobiotics and the Manipulation of Bacteria-Gut-Brain Signals. Trends Neurosci. 2016, 39, 763-781. [CrossRef]

48. Cheng, L.-H.; Liu, Y.-W.; Wu, C.-C.; Wang, S.; Tsai, Y.-C. Psychobiotics in mental health, neurodegenerative and neurodevelopmental disorders. J. Food Drug Anal. 2019, 27, 632-648. [CrossRef] [PubMed]

49. Allen, A.P.; Hutch, W.; Borre, Y.; Kennedy, P.J.; Temko, A.; Boylan, G.; Murphy, E.F.; Cryan, J.F.; Dinan, T.G.; Clarke, G. Bifidobacterium longum 1714 as a translational psychobiotic: Modulation of stress, electrophysiology and neurocognition in healthy volunteers. Transl. Psychiatry 2016, 6, e939. [CrossRef]

50. Gualtieri, P.; Marchetti, M.; Cioccoloni, G.; De Lorenzo, A.; Romano, L.; Cammarano, A.; Colica, C.; Condò, R.; Di Renzo, L. Psychobiotics Regulate the Anxiety Symptoms in Carriers of Allele A of IL-1 $\beta$ Gene: A Randomized, Placebo-Controlled Clinical Trial. Mediat. Inflamm. 2020, 2020, 1-11. [CrossRef]

51. Chao, L.; Liu, C.; Sutthawongwadee, S.; Li, Y.; Lv, W.; Chen, W.; Yu, L.; Zhou, J.; Guo, A.; Li, Z.; et al. Effects of Probiotics on Depressive or Anxiety Variables in Healthy Participants Under Stress Conditions or with a Depressive or Anxiety Diagnosis: A Meta-Analysis of Randomized Controlled Trials. Front. Neurol. 2020, 11, 421. [CrossRef] [PubMed]

52. Zhang, N.; Zhang, Y.; Li, M.; Wang, W.; Liu, Z.; Xi, C.; Huang, X.; Liu, J.; Huang, J.; Tian, D.; et al. Efficacy of probiotics on stress in healthy volunteers: A systematic review and meta-analysis based on randomized controlled trials. Brain Behav. 2020, 10, e01699. [CrossRef]

53. Lin, P.-Y.; Huang, S.-Y.; Su, K.-P. A Meta-Analytic Review of Polyunsaturated Fatty Acid Compositions in Patients with Depression. Biol. Psychiatry 2010, 68, 140-147. [CrossRef]

54. Su, K.-P. Nutrition, psychoneuroimmunology and depression: The therapeutic implications of omega-3 fatty acids in interferon$\alpha$-induced depression. Biomedicine 2015, 5, 1-7. [CrossRef]

55. Appleton, K.M.; Sallis, H.M.; Perry, R.; Ness, A.R.; Churchill, R. Omega-3 fatty acids for depression in adults. Cochrane Database Syst. Rev. 2015, 11. [CrossRef] [PubMed]

56. Guu, T.-W.; Mischoulon, D.; Sarris, J.; Hibbeln, J.; McNamara, R.K.; Hamazaki, K.; Freeman, M.P.; Maes, M.; Matsuoka, Y.J.; Belmaker, R.; et al. A multi-national, multi-disciplinary Delphi consensus study on using omega-3 polyunsaturated fatty acids (n-3 PUFAs) for the treatment of major depressive disorder. J. Affect. Disord. 2020, 265, 233-238. [CrossRef] 
57. Xu, F.; Fan, W.; Wang, W.; Tang, W.; Yang, F.; Zhang, Y.; Cai, J.; Song, L.; Zhang, C. Effects of omega-3 fatty acids on metabolic syndrome in patients with schizophrenia: A 12-week randomized placebo-controlled trial. Psychopharmacology 2018, 236, 1273-1279. [CrossRef]

58. Tang, W.; Wang, Y.; Xu, F.; Fan, W.; Zhang, Y.; Fan, K.; Wang, W.; Zhang, Y.; Zhang, C. Omega-3 fatty acids ameliorate cognitive dysfunction in schizophrenia patients with metabolic syndrome. Brain Behav. Immun. 2020, 88, 529-534. [CrossRef] [PubMed]

59. Bozzatello, P.; De Rosa, M.; Rocca, P.; Bellino, S. Effects of Omega 3 Fatty Acids on Main Dimensions of Psychopathology. Int. J. Mol. Sci. 2020, 21, 6042. [CrossRef] [PubMed]

60. Amminger, G.P.; Schäfer, M.R.; Papageorgiou, K.; Klier, C.; Cotton, S.; Harrigan, S.; Mackinnon, A.; McGorry, P.D.; Berger, G.E. Long-Chain w-3 Fatty Acids for Indicated Prevention of Psychotic Disorders. Arch. Gen. Psychiatry 2010, 67, 146-154. [CrossRef]

61. Amminger, G.P.; Schäfer, M.R.; Schlögelhofer, M.; Klier, C.; McGorry, P.D. Longer-term outcome in the prevention of psychotic disorders by the Vienna omega-3 study. Nat. Commun. 2015, 6, 7934. [CrossRef] [PubMed]

62. McGorry, P.D.; Nelson, B.; Markulev, C.; Yuen, H.P.; Schäfer, M.R.; Mossaheb, N.; Schlögelhofer, M.; Smesny, S.; Hickie, I.; Berger, G.E.; et al. Effect of $\omega-3$ Polyunsaturated Fatty Acids in Young People at Ultrahigh Risk for Psychotic Disorders. JAMA Psychiatry 2017, 74, 19-27. [CrossRef]

63. Berger, M.; Nelson, B.; Markulev, C.; Yuen, H.P.; Schäfer, M.R.; Mossaheb, N.; Schlögelhofer, M.; Smesny, S.; Hickie, I.B.; Berger, G.E.; et al. Relationship Between Polyunsaturated Fatty Acids and Psychopathology in the NEURAPRO Clinical Trial. Front. Psychiatry 2019, 10. [CrossRef]

64. Chasapis, C.T.; Ntoupa, P.-S.A.; Spiliopoulou, C.A.; Stefanidou, M.E. Recent aspects of the effects of zinc on human health. Arch. Toxicol. 2020, 94, 1443-1460. [CrossRef]

65. Yasuda, H.; Tsutsui, T. Infants and elderlies are susceptible to zinc deficiency. Sci. Rep. 2016, 6, 21850. [CrossRef]

66. Jung, A.; Spira, D.; Steinhagen-Thiessen, E.; Demuth, I.; Norman, K. Zinc Deficiency Is associated with Depressive SymptomsResults from the Berlin Aging Study II. J. Gerontol. Ser. A Boil. Sci. Med. Sci. 2016, 72, 1149-1154. [CrossRef]

67. Petrilli, M.A.; Kranz, T.M.; Kleinhaus, K.; Joe, P.; Getz, M.; Johnson, P.; Chao, M.; Malaspina, D. The Emerging Role for Zinc in Depression and Psychosis. Front. Pharmacol. 2017, 8, 414. [CrossRef] [PubMed]

68. Nowak, G. Zinc, future mono/adjunctive therapy for depression: Mechanisms of antidepressant action. Pharmacol. Rep. 2015, 67, 659-662. [CrossRef] [PubMed]

69. Portbury, S.D.; Adlard, P.A. Zinc Signal in Brain Diseases. Int. J. Mol. Sci. 2017, 18, 2506. [CrossRef]

70. Zalachoras, I.; Hollis, F.; Ramos-Fernández, E.; Trovo, L.; Sonnay, S.; Geiser, E.; Preitner, N.; Steiner, P.; Sandi, C.; Morató, L. Therapeutic potential of glutathione-enhancers in stress-related psychopathologies. Neurosci. Biobehav. Rev. 2020, 114, 134-155. [CrossRef]

71. Paydary, K.; Akamaloo, A.; Ahmadipour, A.; Pishgar, F.; Emamzadehfard, S.; Akhondzadeh, S. N-acetylcysteine augmentation therapy for moderate-to-severe obsessive-compulsive disorder: Randomized, double-blind, placebo-controlled trial. J. Clin. Pharm. Ther. 2016, 41, 214-219. [CrossRef] [PubMed]

72. Costa, D.L.C.; Diniz, J.B.; Requena, G.; Joaquim, M.A.; Pittenger, C.; Bloch, M.H.; Miguel, E.C.; Shavitt, R.G. Randomized, DoubleBlind, Placebo-Controlled Trial of N-Acetylcysteine Augmentation for Treatment-Resistant Obsessive-Compulsive Disorder. J. Clin. Psychiatry 2017, 78, e766-e773. [CrossRef]

73. Fineberg, N.A.; Hollander, E.; Pallanti, S.; Walitza, S.; Grünblatt, E.; Dell'Osso, B.M.; Albert, U.; Geller, D.A.; Brakoulias, V.; Reddy, Y.J.; et al. Clinical advances in obsessive-compulsive disorder. Int. Clin. Psychopharmacol. 2020, 35, 173-193. [CrossRef]

74. Berk, M.; Dean, O.M.; Cotton, S.M.; Jeavons, S.; Tanious, M.; Kohlmann, K.; Hewitt, K.; Moss, K.; Allwang, C.; Schapkaitz, I.; et al. The Efficacy of AdjunctiveN-Acetylcysteine in Major Depressive Disorder. J. Clin. Psychiatry 2014, 75, 628-636. [CrossRef] [PubMed]

75. Deepmala; Slattery, J.; Kumar, N.; Delhey, L.; Berk, M.; Dean, O.; Spielholz, C.; Frye, R. Clinical trials of N-acetylcysteine in psychiatry and neurology: A systematic review. Neurosci. Biobehav. Rev. 2015, 55, 294-321. [CrossRef]

76. Kishi, T.; Miyake, N.; Okuya, M.; Sakuma, K.; Iwata, N. N-acetylcysteine as an adjunctive treatment for bipolar depression and major depressive disorder: A systematic review and meta-analysis of double-blind, randomized placebo-controlled trials Psychopharmacology 2020, 237, 3481-3487. [CrossRef]

77. Chakraborty, S.; Tripathi, S.J.; Raju, T.R.; Rao, B.S. Mechanisms underlying remediation of depression-associated anxiety by chronic N-acetyl cysteine treatment. Psychopharmacology 2020, 237, 2967-2981. [CrossRef]

78. Von Känel, R.; Fardad, N.; Steurer, N.; Horak, N.; Hindermann, E.; Fischer, F.; Gessler, K. Vitamin D Deficiency and Depressive Symptomatology in Psychiatric Patients Hospitalized with a Current Depressive Episode: A Factor Analytic Study. PLoS ONE 2015, 10, e0138550. [CrossRef] [PubMed]

79. Sepehrmanesh, Z.; Kolahdooz, F.; Abedi, F.; Mazroii, N.; Assarian, A.; Asemi, Z.; Esmaillzadeh, A. Retracted: Vitamin D Supplementation Affects the Beck Depression Inventory, Insulin Resistance, and Biomarkers of Oxidative Stress in Patients with Major Depressive Disorder: A Randomized, Controlled Clinical Trial. J. Nutr. 2015, 146, 243-248. [CrossRef]

80. Ronaldson, A.; De La Torre, J.A.; Gaughran, F.; Bakolis, I.; Hatch, S.L.; Hotopf, M.; Dregan, A. Prospective associations between vitamin D and depression in middle-aged adults: Findings from the UK Biobank cohort. Psychol. Med. 2020, 1-9. [CrossRef]

81. Amini, S.; Jafarirad, S.; Amani, R. Postpartum depression and vitamin D: A systematic review. Crit. Rev. Food Sci. Nutr. 2018, 59, 1514-1520. [CrossRef] 
82. Barbour, K.A.; Edenfield, T.M.; Blumenthal, J.A. Exercise as a treatment for depression and other psychiatric disorders: A review. J. Cardiopulm. Rehabil. Prev. 2007, 27, 359-367. [CrossRef]

83. RCP. No Health without Public Mental Health: The Case for Action; Position Statement PS4/2010; Royal College of Psychiatrists: London, UK, 2010.

84. Stubbs, B.; Vancampfort, D.; Hallgren, M.; Firth, J.; Veronese, N.; Solmi, M.; Brand, S.; Cordes, J.; Malchow, B.; Gerber, M.; et al. EPA guidance on physical activity as a treatment for severe mental illness: A meta-review of the evidence and Position Statement from the European Psychiatric Association (EPA), supported by the International Organization of Physical Therapists in Mental Health (IOPTMH). Eur. Psychiatry 2018, 54, 124-144. [CrossRef] [PubMed]

85. Firth, J.; Solmi, M.; Wootton, R.E.; Vancampfort, D.; Schuch, F.B.; Hoare, E.; Gilbody, S.; Torous, J.; Teasdale, S.B.; Jackson, S.E.; et al. A meta-review of "lifestyle psychiatry": The role of exercise, smoking, diet and sleep in the prevention and treatment of mental disorders. World Psychiatry 2020, 19, 360-380. [CrossRef]

86. Ashdown-Franks, G.; Firth, J.; Carney, R.; Carvalho, A.F.; Hallgren, M.; Koyanagi, A.; Rosenbaum, S.; Schuch, F.; Smith, L.; Solmi, M.; et al. Exercise as Medicine for Mental and Substance Use Disorders: A Meta-review of the Benefits for Neuropsychiatric and Cognitive Outcomes. Sports Med. 2019, 50, 151-170. [CrossRef]

87. Russell, T.A.; Arcuri, S.M. A Neurophysiological and Neuropsychological Consideration of Mindful Movement: Clinical and Research Implications. Front. Hum. Neurosci. 2015, 9, 282. [CrossRef] [PubMed]

88. Kong, J.; Wilson, G.; Park, J.; Pereira, K.; Walpole, C.; Yeung, A. Treating Depression with Tai Chi: State of the Art and Future Perspectives. Front. Psychiatry 2019, 10, 237. [CrossRef]

89. Liegro, D.; Schiera, G.; Proia, P.; Di Liegro, C.M.; Di Liegro, I. Physical Activity and Brain Health. Genes 2019, 10, 720. [CrossRef]

90. Raglin, S.J. Exercise and Mental Health. Sport Med. 1990, 9, 323-329. [CrossRef]

91. Salmon, P. Effects of physical exercise on anxiety, depression, and sensitivity to stress: A unifying theory. Clin. Psychol. Rev. 2001, 21,33-61. [CrossRef]

92. Mikkelsen, K.; Stojanovska, L.; Polenakovic, M.; Bosevski, M.; Apostolopoulos, V. Exercise and mental health. Maturitas 2017, 106, 48-56. [CrossRef]

93. Riva, A.; Falbo, M.; Passoni, P.; Polizzi, S.; Cattoni, A.; Nacinovich, R. High levels of physical activity in female adolescents with anorexia nervosa: Medical and psychopathological correlates. Eat. Weight Disord. 2021, 1-12. [CrossRef]

94. Balciuniene, V.; Jankauskiene, R.; Baceviciene, M. Effect of an education and mindfulness-based physical activity intervention for the promotion of positive body image in Lithuanian female students. Eat. Weight Disord. 2021, 1-15. [CrossRef]

95. Fossati, M.; Amati, F.; Painot, D.; Reiner, M.; Haenni, C.; Golay, A. Cognitive-behavioral therapy with simultaneous nutritional and physical activity education in obese patients with binge eating disorder. Eat. Weight Disord. Stud. Anorexia Bulim. Obes. 2004, 9, 134-138. [CrossRef]

96. McEwen, B.S.; Akil, H. Revisiting the Stress Concept: Implications for Affective Disorders. J. Neurosci. 2020, 40, 12-21. [CrossRef]

97. McEwen, B.S.; Nasca, C.; Gray, J.D. Stress Effects on Neuronal Structure: Hippocampus, Amygdala, and Prefrontal Cortex. Neuropsychopharmacology 2015, 41, 3-23. [CrossRef]

98. Slavich, G.M. Psychoneuroimmunology of Stress and Mental Health. In The Oxford Handbook of Stress and Mental Health; Oxford Handbooks Online; Oxford University Press: Oxford, UK, 2020. [CrossRef]

99. McEwen, B.S. Neurobiological and Systemic Effects of Chronic Stress. Chronic Stress 2017, 1. [CrossRef] [PubMed]

100. Schiele, M.; Gottschalk, M.; Domschke, K. The applied implications of epigenetics in anxiety, affective and stress-related disorders-A review and synthesis on psychosocial stress, psychotherapy and prevention. Clin. Psychol. Rev. 2020, 77, 101830. [CrossRef]

101. Bey, K.; Campos-Martin, R.; Klawohn, J.; Reuter, B.; Grützmann, R.; Riesel, A.; Wagner, M.; Ramirez, A.; Kathmann, N. Hypermethylation of the oxytocin receptor gene (OXTR) in obsessive-compulsive disorder: Further evidence for a biomarker of disease and treatment response. Epigenetics 2021, 1-11. [CrossRef] [PubMed]

102. Bottaccioli, A.G.; Bottaccioli, F.; Minelli, A. Stress and the psyche-brain-immune network in psychiatric diseases based on psychoneuroendocrineimmunology: A concise review. Ann. N. Y. Acad. Sci. 2018, 1437, 31-42. [CrossRef]

103. Miller, C.W.T. Epigenetic and Neural Circuitry Landscape of Psychotherapeutic Interventions. Psychiatry J. 2017, 2017, 1-38. [CrossRef]

104. Yehuda, R.; Daskalakis, N.P.; Desarnaud, F.; Makotkine, I.; Lehrner, A.L.; Koch, E.; Flory, J.D.; Buxbaum, J.D.; Meaney, M.J.; Bierer, L.M. Epigenetic Biomarkers as Predictors and Correlates of Symptom Improvement Following Psychotherapy in Combat Veterans with PTSD. Front. Psychiatry 2013, 4, 118. [CrossRef] [PubMed]

105. Vinkers, C.H.; Geuze, E.; van Rooij, S.J.H.; Kennis, M.; Schür, R.R.; Nispeling, D.M.; Smith, A.K.; Nievergelt, C.M.; Uddin, M.; Rutten, B.P.F.; et al. Successful treatment of post-traumatic stress disorder reverses DNA methylation marks. Mol. Psychiatry 2019, 26, 1264-1271. [CrossRef]

106. Bower, J.E.; Irwin, M.R. Mind-body therapies and control of inflammatory biology: A descriptive review. Brain Behav. Immun. 2016, 51, 1-11. [CrossRef]

107. Bottaccioli, F.; Carosella, A.; Cardone, R.; Mambelli, M.; Cemin, M.; D’Errico, M.M.; Ponzio, E.; Bottaccioli, A.G.; Minelli, A. Brief Training of Psychoneuroendocrinoimmunology-Based Meditation (PNEIMED) Reduces Stress Symptom Ratings and Improves Control on Salivary Cortisol Secretion Under Basal and Stimulated Conditions. Explor. J. Sci. Health 2014, 10, 170-179. [CrossRef] [PubMed] 
108. Dasanayaka, N.N.; Sirisena, N.D.; Samaranayake, N. The effects of meditation on length of telomeres in healthy individuals: A systematic review. Syst. Rev. 2021, 10,1-6. [CrossRef] [PubMed]

109. Shields, G.S.; Spahr, C.M.; Slavich, G.M. Psychosocial Interventions and Immune System Function. JAMA Psychiatry 2020, 77, 1031. [CrossRef] [PubMed] 